OPEN ACCESS

Edited by:

Laurent Dufossé,

Université de la Réunion, France

Reviewed by:

Zhilong Wang,

Shanghai Jiao Tong University, China Iramaia Angelica Neri-Numa,

Campinas State University, Brazil

*Correspondence: Adriano Brandell abrand@ufrgs.br

Specialty section: This article was submitted to

Sustainable Food Processing, a section of the journal

Frontiers in Sustainable Food Systems

Received: 01 August 2020

Accepted: 24 August 2020

Published: 30 September 2020

Citation:

Pailliè-Jiménez ME, Stincone $P$ and Brandelli A (2020) Natural Pigments of

Microbial Origin.

Front. Sustain. Food Syst. 4:590439.

doi: 10.3389/fsufs.2020.590439

\section{Natural Pigments of Microbial Origin}

\author{
Maria Elisa Pailliè-Jiménez, Paolo Stincone and Adriano Brandelli* \\ Laboratório de Bioquímica e Microbiologia Aplicada, Departamento de Ciência de Alimentos, Universidade Federal do Rio \\ Grande do Sul, Porto Alegre, Brazil
}

The world demands new solutions and products to be used as dyes for industrial applications. Microbial pigments represent an eco-friendly alternative as they can be produced in large amounts through biotechnological processes and do not present environmental risks, as they are easily decomposable. Moreover, some of these metabolites are recognized for their biological activities, which qualify them for potential uses as food colorants and nutraceuticals, protecting against degenerative diseases related with oxidative stress. Because of their genetic simplicity as compared with plants, microorganisms may be a better source to understand biosynthetic mechanisms and to be engineered for producing high pigment yields. Despite the origin of the pigmented microorganism, it seems very important to develop protocols using organic industrial residues and agricultural byproducts as substrates for pigment production and find novel green strategies for rapid pigment extraction. This review looks for the most recent studies that describe microbial pigments from microalgae, fungi, and bacteria. In particular, the underexploited tools of omics science such as proteomics and metabolomics are addressed. The use of techniques involving mass spectrometry, allows to identify different protein and metabolite profiles that may be associated with a variety of biotechnologically-relevant pathways of pigment synthesis.

Keywords: bioactive metabolites, microbial pigments, extraction, proteomics, metabolomics

\section{INTRODUCTION}

Pigments have become an essential part of our daily lives and have extensive applications in many areas, such as agriculture, textiles, cosmetics, pharmaceuticals, foods, among others (Yusuf et al., 2017; Venil et al., 2020a). Synthetic dyes have been produced on a large scale to respond the high demand for improving the color appearance of diverse products. They still have an advantage in terms of large-scale production at economical price with consistent color quality and numerous color variation outweigh the benefits of natural dyes. However, several studies show that synthetic dyes can cause adverse effects in terms of consumer and occupational health and have a negative impact on the environment (Fuck et al., 2018; Zerin et al., 2020). Synthetic dyes are non-renewable, non-biodegradable, sometimes carcinogenic, and cause toxic waste pollution, presenting a huge challenge in disposing the byproduct waste in a cost effective way (Azman et al., 2018; Ramesh et al., 2019).

Many natural pigments besides fulfilling their function of giving color are known as interesting bioactive compounds with potential health benefits. These compounds have a wide range of applications in medicine, food, pharmacology, agrochemicals, cosmetics, among others (Venil et al., 2020b). Numerous microbial bioactive pigments have been discovered and many of them show antioxidant, anti-inflammatory, and/or antimicrobial properties (Ramesh et al., 2019). 
The high demand for natural products is impelling an exponentially growing market, and the annual increase rate of the colorant market is estimated at $\sim 7 \%$ and is expected to reach $\$ 7.79$ billion by the year 2020 (Dikshit and Tallapragada, 2018). Thus, the organics market and pigment industries represent vast commercial sectors that would be shortly dominated by microbial pigments (Novoveská et al., 2019). In comparison to plant and animal sources, microbial pigment production by fermentation technology is more dynamic and economic, resulting in biodegradable compounds that may have wide industrial applications as colorants (Silva et al., 2019; Venil et al., 2020a). Although microbial pigments are not widespread in colorant formulations, they represent an important alternative that has the long-term ability to compete with synthetic dyes (Zerin et al., 2020). The successful application of microbial pigments relies on high production yields, reasonable production costs, regulatory approval, pigment characterization, and stability to environmental factors such as temperature and light (MoralesOyervides et al., 2017).

In this mini-review, recent studies describing pigments extracted from microalgae, fungi and bacteria are discussed, including potential industrial applications. This article focuses on the importance of finding natural microbial bioactive pigments and the need of understanding the metabolic pathways involved in their synthesis. The requirement for green methodologies for rapid pigment extraction and purification is also addressed.

\section{MICROBIAL BIOACTIVE PIGMENTS}

Pigments are extensively produced among microorganisms, including microalgae, fungi and bacteria. Although there is still no precise classification of all pigments that can be naturally synthesized by microorganisms, in vitro and in vivo studies indicate that some of these molecules can be helpful in the prevention or treatment of degenerative diseases (Shen et al., 2018; Sajjad et al., 2020). Some examples of microbial pigments showing bioactivities are presented in Supplementary Table 1.

\section{Bioactive Pigments From Microalgae}

Microalgae genera as Nostoc, Dunaliella, Scenedesmus, Nannochloropsis, Haematococcus, Muriellopsis, Chlorella, Phaeodactylum, Spirulina, Artrhospira, Porphyridium, Agardhiella, Polysiphonia produce different groups of pigments, such as carotenoids, chlorophylls and phycobiliproteins (PBPs), known as non-toxic water-soluble proteins mostly found in Rhodophyta (red algae), Cyanobacteria, and Cryptophyta (Yusuf et al., 2017; Noreña-Caro and Benton, 2018; Arashiro et al., 2020). Due to their strong absorbance and fluorescence properties as well as antioxidant and free radical scavenging activities, PBPs have been widely employed in food, cosmetics, pharmaceutical, and biomedical industries (Sonani et al., 2016). Some antioxidant pigments from microalgae are shown in Supplementary Figure 1. Microalgae pigments have additional biological functions, such as anti-inflammatory, antiangiogenic, neuro- and hepatic-protective, antiviral, antiobesity, antidiabetic, anticancer, and anti-osteoporotic. They also may help to regulate cardiovascular diseases, cognitive function, protect from UV rays, enhance immune functions, present antiaging property, and prevent some blood-related disorders (Ambati et al., 2018; Saini et al., 2018).

Microalgae pigments have high commercial value as natural colorants in the nutraceutical, cosmetic, and pharmaceutical industries, as well as applications in clinical research and molecular biology, and as natural dyes in the textile industries, painting and color industries, food colorant and feed additive for poultry (de Morais et al., 2018; Okolie et al., 2019). Bottlenecks for effective pigment production should be overcome, and potential genetic and metabolic approaches could be used to achieve cost-intensive productivity (Saini et al., 2020).

\section{Bioactive Pigments From Yeast and Filamentous Fungi}

Fungi belonging to the Monascaceae, Trichocomaceae, Nectriaceae, Hypocreaceae, Pleosporaceae, Cordycipitaceae, Xylariaceae, Chaetomiaceae, Sordariaceae, Chlorociboriaceae families have been described as potent pigment producers (Ramesh et al., 2019). Certain genera of yeast like Rhodotorula, Sporidiobolus, Sporobolomyces, Xanthophyllomyces, and Pichia have also been recognized as pigment producers. Some of them have been reported to be prolific producers of torulene and torularhodin, $\beta$-carotene, poly-hydroxy carotenoids among others (Cipolatti et al., 2019; Kot et al., 2019).

Fungal pigments are mostly carotenoids, melanins and polyketides, namely flavins, phenazines, quinones, monascins, violacein and indigo, presenting a wide spectrum of colors (Supplementary Figure 2). Valuable bioactive properties like anticancer, antioxidant, antimicrobial, anti-inflammatory and immune-suppressor have been associated with fungal pigments (Mapari et al., 2009; Lopes et al., 2013). Thus, they present applications in the food and healthcare industries, as dyeing agents in the textile industry, and as cosmetic additives due to the capacity of absorb harmful UV rays (Chen et al., 2019; Lagashetti et al., 2019; Sajjad et al., 2020).

\section{Bioactive Pigments From Bacteria and Actinobacteria}

Most common bacterial pigments are carotenoids, aryl polyenes that in some cases are esterified with a dialkylresorcinol system, melanins, phenazines, quinones, tambjamines, prodigiosines, violacein (Supplementary Figure 3). These pigments are reported for their antioxidant and UV protection properties, and many bacterial pigments demonstrated potential biomedical applications such as antimicrobial, antimalarial, and anticancer properties (Sajjad et al., 2020).

The most common pigments from actinobacteria are melanins with colors ranging from black through brown to olive, carotenoids with colors ranging from red, yellow, and pink through to violet and thirdly, actinorhodin-related blue pigments (Rao et al., 2017). Pigments from the carotenoids group are also described, showing antioxidant activities and being harmless for safe use as a natural colorant in cosmetic, food, pharmaceutical and textile industries (Parmar and Singh, 2018). 
TABLE 1 | Agro-industrial by-products used to produce orange and red pigments from Monascus strains.

\begin{tabular}{|c|c|c|c|}
\hline Strain & Substrate & Process $^{a}$ & References \\
\hline M. ruber LEB A4-5 & Corn steep liquor & $\mathrm{SmF}, 30^{\circ} \mathrm{C}, 300 \mathrm{rpm}$ & Hamano and Kilikian, 2006 \\
\hline M. purpureus NRRL 1992 & Grape waste & $\mathrm{SmF}, 25^{\circ} \mathrm{C}, 100 \mathrm{rpm}$ & Silveira et al., 2008 \\
\hline M. ruber MTCC2326 & Rice brokens & SST & Rajagopal et al., 2009 \\
\hline M. purpureus CMU001 & Meal from corn, peanut, soybean, coconut residue & SST, $30^{\circ} \mathrm{C}, 14$ days & Nimnoi and Lumyong, 2009 \\
\hline M. purpureus NRRL 1992 & Sugarcane bagasse & $\mathrm{SmF}, 27^{\circ} \mathrm{C}, 125 \mathrm{rpm}$ & Silveira et al., 2013 \\
\hline M. purpureus LQ-6 & Rice straw hydrolysate & $\mathrm{SmF} 30^{\circ} \mathrm{C}, 150 \mathrm{rpm}$ & Liu et al., 2019 \\
\hline M. purpureus CMU001 & Brewer's spent grain & SmF, pH 6.5, 350 rpm & Silbir and Goksungur, 2019 \\
\hline M. purpureus FTC5357 & Oil palm frond & SST, $30^{\circ} \mathrm{C}$ & Daud et al., 2020 \\
\hline
\end{tabular}

a SST, solid-state fermentation; SmF, submerged fermentation.

\section{MICROBIAL PIGMENT PRODUCTION USING AGRO-INDUSTRIAL BYPRODUCTS}

A relevant aspect for the sustainable production of microbial pigments is the definition of an appropriate growth media, which should be cost-effective and result in high pigment yields. In this regard, the importance of recycling agro-industrial byproducts as growth substrates for microbial pigment production has been reported (Korumilli et al., 2020; Venil et al., 2020a). Bioconversion of agri-food waste to value-added products is very important toward zero waste and circular economy concepts. To reduce the environmental burden, food researchers are seeking strategies to utilize agro-industrial residues for microbial pigments production and further biotechnological exploitation in functional foods or value-added products (Usmani et al., 2020). Diverse agro-industrial wastes have been investigated for production of the well-known Monascus pigments (Table 1), and some processes using such inexpensive substrates presented high pigment yields (Embaby et al., 2018). In addition, industrial wastewaters are successfully used for production of phycocyanins and carotenoid pigments by microalgae (Singh et al., 2019; Arashiro et al., 2020).

Intracellular carotenoids ( $\beta$-carotene, $\gamma$-carotene, torulene, and torularhodin) from Rhodotorula species have been produced by using different agro-industrial byproducts as sugarcane bagasse, wheat bran, rice bran, silage, whey, raw glycerol, corn steep liquor, sugarcane molasses, waste chicken feathers, fruit waste extract, and many others (Sharma and Ghoshal, 2019; Korumilli et al., 2020). These pigments could have applications in food and feed as well as in health, pharmaceutical products and cosmetics, generating a market value expected to reach over $\$ 2.0$ billion by 2022 (Elfeky et al., 2019; Tang et al., 2019).

The economic viability of industrial-scale facilities that produce powdered astaxanthin and astaxanthin oil mixture from wheat bran and olive pomace was evaluated in a simulated solid-state fermentation study. An economic analysis was conducted for different fermentation conditions to identify the plant capacity that optimizes the process economics for a cost-effective bioprocess. The techno-economic analysis demonstrated that producing astaxanthin from agro-industrial waste is a feasible and promising technology (Dursun et al., 2020).

\section{GREEN PROTOCOLS ON MICROBIAL PIGMENTS}

\section{Extraction Protocols}

Microorganisms offer a tremendous diversity of pigmented molecules, but the methodologies and protocols applied for their extraction and purification are tedious, involving multiple steps, the use of diverse organic solvents, and still giving incongruent results. The variety of extraction protocols employed for microbial pigment extraction can be seen in Supplementary Table 1. The choice of extraction protocol is crucial, as the extraction solvents and conditions can drastically influence the final composition, quality, and efficiency of the process (Soares et al., 2016).

In order to minimize the use of organic solvents and preserve as much as possible the qualitative and quantitative compositions of the pigmented molecules, ecofriendly methodologies have been investigated. Although these techniques have been employed for extraction of many bioactive substances, their effective application for extraction microbial pigments should be further exploited (Kalra et al., 2020; Martínez et al., 2020). Some characteristics, advantages and disadvantages of these green methodologies are detailed in Table 2.

Ultrasound-assisted extraction (UAE) has been recognized as an efficient and environmentally safe extraction method. Enzymatic UAE was used for obtaining the natural food colorant C-phycocyanin from dry biomass of Arthrospira platensis and this method resulted in the highest yield $(92.73 \mathrm{mg} / \mathrm{g}$ dry biomass) and extraction efficiency (78\%) among the methods studied (Tavanandi and Raghavarao, 2019). Microwave assisted extraction (MEA) has been considered an excellent technique for the isolation of microalgae pigments due to its reproducibility, rapidity, uniform heating, and high extraction yields (Pasquet et al., 2011). As the most safe, non-toxic, non-flammable, noncorrosive solvent, water can be used as a green solvent in MAE and UAE for efficient extraction of several metabolites from 
TABLE 2 | Green methodologies for microbial pigment extraction ${ }^{\mathrm{a}}$.

\begin{tabular}{|c|c|c|c|c|}
\hline Method & Driving force & Principle & Advantages & Disadvantages \\
\hline $\begin{array}{l}\text { Ultrasound assisted } \\
\text { extraction (UAE) }\end{array}$ & Acoustic cavitation & $\begin{array}{l}\text { High-intensity ultrasound } \\
\text { pressure waves accelerate the } \\
\text { tissue rupture and releasing } \\
\text { intracellular substances into a } \\
\text { small amount of solvent }\end{array}$ & $\begin{array}{l}\text { Fast, improved extraction yields, } \\
\text { apparatus simple and easy to } \\
\text { handle, safe, reduced solvent } \\
\text { amount }\end{array}$ & $\begin{array}{l}\text { Filtration step required, possible } \\
\text { deterioration of compounds at } \\
\text { high frequencies }\end{array}$ \\
\hline $\begin{array}{l}\text { Microwave assisted } \\
\text { extraction (MAE) }\end{array}$ & Microwave power & $\begin{array}{l}\text { Microwave radiation frequencies } \\
\text { ranging from } 300 \mathrm{MHz} \text { to } 300 \\
\mathrm{GHz} \text { as source of energy }\end{array}$ & $\begin{array}{l}\text { Fast, reproducible, uniform } \\
\text { heating, high extraction yields, } \\
\text { easy to handle, reduced solvent } \\
\text { amount }\end{array}$ & $\begin{array}{l}\text { Filtration step required, } \\
\text { expensive, risk of explosion } \\
\text { depending on solvent }\end{array}$ \\
\hline $\begin{array}{l}\text { Pressurized liquid extraction } \\
\text { (PLE) }\end{array}$ & $\begin{array}{l}\text { Heat plus solvent under } \\
\text { pressure }\end{array}$ & $\begin{array}{l}\text { Automated advanced technique } \\
\text { to conventional solvent } \\
\text { extraction methods such as } \\
\text { reflux, Soxhlet extraction, } \\
\text { percolation or maceration }\end{array}$ & $\begin{array}{l}\text { Reduced extraction time, } \\
\text { reproducible, no filtering } \\
\text { required }\end{array}$ & $\begin{array}{l}\text { Possible degradation of } \\
\text { thermo-labile compounds }\end{array}$ \\
\hline $\begin{array}{l}\text { Supercritical fluid extraction } \\
\text { (SFE) }\end{array}$ & $\begin{array}{l}\text { Pressure plus supercritical } \\
\text { fluid }\end{array}$ & $\begin{array}{l}\text { Use of liquefied } \mathrm{CO}_{2} \text { as the } \\
\text { supercritical fluid for the } \\
\text { extraction of bioactive } \\
\text { molecules from solid matrices }\end{array}$ & $\begin{array}{l}\text { Fast, high selectivity, extraction } \\
\text { of thermo-labile substances }\end{array}$ & $\begin{array}{l}\text { High cost of equipment, poor } \\
\text { extraction of polar substances, } \\
\text { many parameters to optimize }\end{array}$ \\
\hline $\begin{array}{l}\text { Pulsed electric field assisted } \\
\text { extraction (PFE) }\end{array}$ & Electric field & $\begin{array}{l}\text { Electroporation or } \\
\text { electro-permeabilization, } \\
\text { exposing the sample to short } \\
\text { impulses of high intensity } \\
\text { electric field }\end{array}$ & $\begin{array}{l}\text { Use of green solvents, easy to } \\
\text { scale up, extraction of } \\
\text { thermo-labile substances, direct } \\
\text { extraction from biomass }\end{array}$ & $\begin{array}{l}\text { High cost of equipment, } \\
\text { affected by air bubbles, } \\
\text { efficiency highly dependable on } \\
\text { medium conductivity }\end{array}$ \\
\hline $\begin{array}{l}\text { Ionic liquids assisted } \\
\text { extraction (ILE) }\end{array}$ & Solvent contact & $\begin{array}{l}\text { Tailor-made solvents for } \\
\text { extensive extraction of natural } \\
\text { compounds }\end{array}$ & $\begin{array}{l}\text { Direct extraction from biomass, } \\
\text { enhanced extraction yields }\end{array}$ & $\begin{array}{l}\text { Cost for larger industrial use, } \\
\text { limited availability, relative higher } \\
\text { viscosity }\end{array}$ \\
\hline
\end{tabular}

${ }^{a}$ Compiled from Medina-Torres et al. (2017), Kalra et al. (2020).

microbial matrices. An alternative to traditional extraction by organic solvents is to accomplish the extraction by $\mathrm{CO}_{2}$ based supercritical fluid extraction (SFE) method (Da Silva et al., 2016; Khaw et al., 2017). SFE has been recognized as a green sustainable technique for the selective isolation of molecules, including thermo-labile compounds. The employment of SFE for carotenoids extraction from diverse substrates from laboratory to the commercial scale have been reported (Kitada et al., 2009; Goto et al., 2015).

In addition, pressurized liquid extraction (PLE; also known as accelerated solvent extraction-ASE) (Lebeau et al., 2017), pulsed electric field (PEF)-assisted extraction (Martínez et al., 2020), and ionic liquids (IL)-assisted extraction (Mussagy et al., 2019) have been described as efficient and feasible green methods to improve the extraction yield of pigments from microbial biomass. All these techniques have pros and cons (Table 2) and despite the advances in extraction methodologies, improved green methods are still necessary.

\section{Purification Protocols}

Column chromatography and preparative thin layer chromatography are usual techniques for pigment purification. Polymeric resins and non-ionic adsorption resins have been used for the separation and purification of microbial pigments. The selected resin will adsorb the target pigment from the culture broth, making the process easier, with lower operational cost and solvent consumption. This method yielded a concentrated and partially purified pigment from $S$. marcescens with total recovery of $83 \%$, which was much higher as compared to other conventional methods (Wang et al., 2004). A study using macroporous polymeric adsorption resins demonstrated the promising potential of HP-20 resins for the recovery and purification of prodigiosin from Serratia marcescens fermentation broth (Juang and Yeh, 2014).

Despite these methods can be adequate to reach the required purity for commercial applications, several technological advances are still necessary to improve the separation and purification of pigments from culture broth to reduce the energy and process costs (Wang et al., 2004; Venil et al., 2014).

\section{HIGH-THROUGHPUT METHODOLOGIES IN MICROBIAL PIGMENT PRODUCTION}

The emerging of "omics" tools for large-scale microbial examination at the molecular level have proven to be effective for bio-prospection and characterization of microorganisms and their metabolites (Luzzatto-Knaan et al., 2015). Although these methodologies have been widely applied to microbiological research, they are still underestimated for the study of pigment synthesis by microorganisms. Thus, high throughput technologies can be useful to provide advanced knowledge on biosynthetic pathways and discovery of new microbial pigments. A possible workflow considering the use of "omics" sciences coupled with the well-studied and advanced genetic methodologies is presented in Supplementary Figure 4. 


\section{Genomics and Metagenomics}

Genomics approach may help the searching for gene clusters involved in pigment biosynthesis. The genomic analysis shows the microbial capacity to produce specific secondary metabolites even if they remain silent or criptic under laboratorial culture conditions. Indeed, approximately $90 \%$ of the biosynthetic gene clusters for secondary metabolites has been observed to be included into these categories (Baltz, 2017). Different recent works include the detection of pigment gene clusters (Liao et al., 2019; Xu et al., 2019; Mandakovic et al., 2020). The genome information given by the industrial strain M. purpureus YY-1, compared with closely related filamentous fungi, showed adaptation to starch-based foods. Moreover, correlated transcriptomics analysis revealed the highly expressed genes for pigments production on carbon starvation, providing useful insights for industrial applications (Yang et al., 2015). Pangenomics analysis was used for identification of the tryptophan genes cluster as indispensable on the production of blue pigments by Pseudomonas fluorescens (Andreani et al., 2015). Moreover, genomics information becomes indispensable for improving microbial pigment production through genetic manipulation (Venil et al., 2020b), and supports the identification and/or confirmation of produced pigments by novel microorganisms (Varasteh et al., 2020).

Metagenomics analysis of assembled genomes from different microbial phyla, even from uncultured samples, permits to acquire information from unknown microorganisms. In this regard, next-generation sequencing platforms have given a strong contribution for the metagenomics study of microbial networks in a community (Jindal, 2020). This latter omics methodology permitted to overcome the problem of uncultivable microorganisms and to identify novel pigments from extremophile microorganisms, for example from hot springs (Thiel et al., 2019) or marine sources (Rambo et al., 2020). Metagenomics may overcome some limitations of normal laboratory methodologies to study microorganisms from these extreme environments (Stincone and Brandelli, 2020). Thus, metagenomics can be very useful to prospect novel microbial pigments.

\section{Proteomics and Metabolomics}

Proteomics is a powerful tool for identification of proteins on a large scale, providing a general overview of the total proteins expressed by an organism under determined conditions (Aslam et al., 2017). The comparative proteomics approach has been used to study proteins related to pigment production. Although works are mostly associated with plant pigments, more recently the microbial pigments production has been investigated by proteomics approach. These studies include the synthesis of pigments by Monascus purpureus under high ammonium chloride concentration (Zhou et al., 2020), the polyextremophilic bacterium Deinococcus radiodurans in response to oxidative stress (Gao et al., 2020), the pigmentation factors in Pseudomonas fluorescens ITEM 17298 (Quintieri et al., 2019), and the air-isolated Aspergillus sp. from International Space Station (Blachowicz et al., 2019).
Metabolomics include all the analytical profiling techniques that permit the identification of a large number of metabolites present in biological samples. Combining highthroughput analytical chemistry and multivariate data analysis, metabolomics offers a window on metabolic mechanisms (Manchester and Anand, 2017). In recent studies, untargeted metabolomics approach was selected as a good methodology to search and study the metabolic routes on pigments synthesis (Parrot et al., 2019; Fan et al., 2020). The combination of quantitative proteomics and metabolomics define correlations between abundance of natural products, such as pigments, and changes in the microbial protein poll, allowing the detection of biosynthetic enzyme clusters of the producing strains (Song et al., 2014; Du and Van Wezel, 2018).

\section{Pigment Synthesis Through Genetic Engineering}

Previous studies have shown that "omics" strategies can help in understanding the roadblocks in the production of pigments and to counter that, genetic engineering technologies can be used to increase pigment production for large scale applications (He et al., 2017; Lin et al., 2017). The overexpression of gene clusters associated with pigment biosynthesis can be achieved through strategies activating transcriptionally silent gene clusters and/or recombinant DNA technologies to increase the biosynthesis of secondary metabolites (Kjærbølling et al., 2019). The integration of "omics" results with genetic engineering approaches sometimes can support the analysis of the biosynthesis of microbial secondary metabolites and help on the development of a consolidate integrated strategy for the discovery of bioactive compounds (Palazzotto and Weber, 2018), including pigments.

A recent review detailed the recent advancements on engineered microbial systems contextualizing the possibility of using agri-food waste biomass as growth substrates (Usmani et al., 2020). From our point of view, this is a very interesting aspect to be exploited by pigmented microorganisms, eventually with bioactivities, by using organic wastes supporting a circular economy. Recent works have reinforced the use of metabolic engineered microorganisms for pigments production (Mohammad et al., 2020) and the application of these methodologies to produce microalgae biopigments (Saini et al., 2020). Different research groups around the world are directing the research to the use of metabolic and genetic engineering for pigment production, including the use in foods subjected to regulatory approval (Sen et al., 2019; Kalra et al., 2020; Venil et al., 2020b).

\section{CONCLUSIONS AND PERSPECTIVES}

Microbial pigments have huge potential applications in multiple areas, including health, since some of them display relevant biological activities. The advances in microbial biotechnology have been useful for improvement of cultivation protocols, allowing maximum pigment yields by growing dyed microorganisms on waste materials. The omics science can 
helps on understanding of biosynthetic routes, thus providing important information that can be used to stimulate the production of these pigments for possible use in biotechnological scale. Future research should be conducted for improvement in methodologies for pigment extraction and purification, seeking for environmentally safe approaches reducing solvent use and energy inputs, easy methodologies that allows feasible scale-up. Regulatory challenges are associated with the use of microbial pigments in foods, nutraceuticals and cosmetics as the current legislation is often based on local and tradition. Although native pigment-producing microbes represent the greater regulatory and consumer acceptance, the main challenge to commercialize either native or non-native microbial pigments is the regulatory hurdles and associated consumers' preference. In addition, an adequate toxicity evaluation of promising bioactive pigments is necessary to warrant the delivery of such natural products with health benefits. Furthermore, a clear multidisciplinary aspect is associated with microbial bioactive pigments, connecting biotechnology, food and biomedical sciences to provide

\section{REFERENCES}

Ambati, R. R., Gogisetty, D., Gokare, R., Ravi, S., Narasimharao, P. B., Bo, L., et al. (2018). Industrial potential of carotenoid pigments from microalgae: current trends and future prospects. Crit. Rev. Food Sci. Nutr. 59, 1880-1902. doi: 10.1080/10408398.2018.1432561

Andreani, N. A., Carraro, L., Martino, M. E., Fondi, M., Fasolato, L., Miotto, G., et al. (2015). A genomic and transcriptomic approach to investigate the blue pigment phenotype in Pseudomonas fluorescens. Int. J. Food Microbiol. 213, 88-98. doi: 10.1016/j.ijfoodmicro.2015.05.024

Arashiro, L. T., Boto-Ordoñez, M., van Hulle, S. W. H., Ferrer, I., Garfí, M., and Rosseau, D. P. L. (2020). Natural pigments from microalgae grown in industrial wastewater. Bioresour. Technol. 303:122894. doi: 10.1016/j.biortech.2020.122894

Aslam, B., Basit, M., Nisar, M. A., Khurshid, M., and Rasool, M. H. (2017). Proteomics: technologies and their applications. J. Chromatogr. Sci. 55, 182-196. doi: 10.1093/chromsci/bmw167

Azman, A. S., Mawang, C.-I., and Abu, B. S. (2018). Bacterial pigments: the bioactivities and as an alternative for therapeutic applications. Nat. Prod. Commun. 13, 1747-1754. doi: 10.1177/1934578X1801301240

Baltz, R. H. (2017). Gifted microbes for genome mining and natural product discovery. J. Ind. Microbiol. Biotechnol. 44, 573-588. doi: 10.1007/s10295-016-1815-x

Blachowicz, A., Chiang, A. J., Romsdahl, J., Kalkum, M., and Wang, C. C. C. (2019). Proteomic characterization of Aspergillus fumigatus isolated from air and surfaces of the international space station. Fungal Genet. Biol. 124, 39-46. doi: 10.1016/j.fgb.2019. 01.001

Chen, W., Feng, Y., Molnar, I., and Chen, F. (2019). Nature and nurture: confluence of pathway determinism with metabolic and chemical serendipity diversifies Monascus azaphilone pigments. Nat. Prod. Rep. 36, 561-572. doi: 10.1039/C8NP00060C

Cipolatti, E., Remedi, R., Sá, C., Rodrigues, A., Ramos, J., Burkert, C., et al. (2019). Use of agroindustrial byproducts as substrate for production of carotenoids with antioxidant potential by wild yeasts. Biocatal. Agric. Biotechnol. 20:101208. doi: $10.1016 /$ j.bcab.2019.101208

Da Silva, R. P., Rocha-Santos, T. A., and Duarte, A. C. (2016). Supercritical fluid extraction of bioactive compounds. Trends Anal. Chem. 76, 40-51. doi: 10.1016/j.trac.2015.11.013

Daud, N., Said, F., Ramu, M., and Yasin, N. (2020). Evaluation of bio-red pigment extraction from Monascus purpureus FTC5357. IOP Conf. Ser. Mater. Sci. Eng. 736:022084. doi: 10.1088/1757-899X/736/2/022084 molecules with both colorant and nutraceutical functions, and potential health benefits.

\section{AUTHOR CONTRIBUTIONS}

MP-J and PS participate in bibliography research and writting of the manuscript. $\mathrm{AB}$ performed the conceptualization and writing. All authors revised the final version of the manuscript.

\section{FUNDING}

MP-J was Ph.D. fellowship of Colfuturo program (Bogota, Colombia).

\section{SUPPLEMENTARY MATERIAL}

The Supplementary Material for this article can be found online at: https://www.frontiersin.org/articles/10.3389/fsufs. 2020.590439/full\#supplementary-material

de Morais, M. G. D., Prates, D. F., Moreira, J. B., Duarte, J. H., and Costa, J. A. V. (2018). Phycocyanin from microalgae: properties, extraction and purification, with some recent applications. Ind. Biotechnol. 14, 30-37. doi: 10.1089/ind.2017.0009

Dikshit, R., and Tallapragada, P. (2018). "Comparative study of natural and artificial flavoring agents and dyes", in Natural and Artificial Flavoring Agents and Food Dyes, eds. A. M. Grumezescu, A. M. Holban (London: Academic Press), 83-111. doi: 10.1016/B978-0-12-811518-3.00003-X

$\mathrm{Du}$, C., and Van Wezel, G. P. (2018). Mining for microbial gems : integrating proteomics in the postgenomic natural product discovery pipeline. Proteomics 18:e1700332. doi: 10.1002/pmic. 201700332

Dursun, D., Koulouris, A., and Dalgiç, A. C. (2020). Process simulation and techno economic analysis of astaxanthin production from agro-industrial wastes. Waste Biomass Valor. 11, 943-954. doi: 10.1007/s12649-018-0439-y

Elfeky, N., Elmahmoudy, M., Zhang, Y., Guo, J. L., and Bao, Y. (2019). Lipid and carotenoid production by Rhodotorula glutinis with a combined cultivation mode of nitrogen, sulfur, and aluminium stress. Appl. Sci. 9:2444. doi: 10.3390/app9122444

Embaby, A. M., Hussein, M. N., and Hussein, A. (2018). Monascus orange and red pigments production by Monascus purpureus ATCC16436 through co-solid state fermentation of corn cob and glycerol: an eco-friendly environmental low cost approach. PLoS ONE 13:e027755. doi: 10.1371/journal.pone.0207755

Fan, M., Lian, W., Li, T., Fan, Y., Rao, Z., Li, Y., et al. (2020). Metabolomics approach reveals discriminatory metabolites associating with the blue pigments from Vaccinium bracteatum thunb. leaves at different growth stages. Ind. Crop. Prod. 147:112252. doi: 10.1016/j.indcrop.2020.112252

Fuck, W. F., Brandelli, A., and Gutterres, M. (2018). Special review paper: leather dyeing with biodyes from filamentous fungi. J. Am. Leather Chem. Assoc. $113,299-310$.

Gao, L., Zhou, Z., Chen, X., Zhang, W., Lin, M., and Chen, M. (2020). Comparative proteomics analysis reveals new features of the oxidative stress response in the polyextremophilic bacterium Deinococcus radiodurans. Microorganisms 8:451. doi: 10.3390/microorganisms8030451

Goto, M., Kanda, H., Wayudiono, and Machmudah, S. (2015). Extraction of carotenoids and lipids from algae by supercritical $\mathrm{CO}_{2}$ and subcritical dimethyl ether. J. Supercrit. Fluid. 96, 245-251. doi: 10.1016/j.supflu.2014.10.003

Hamano, P. S., and Kilikian, B. V. (2006). Production of red pigments by Monascus ruber in culture media containing corn steep liquor. Braz. J. Chem. Eng. 23, 443-449. doi: 10.1590/S0104.66322006004000002

He, X., Li, Y., Lawson, D., and Xie, D. (2017). Metabolic engineering of anthocyanins in dark tobacco varieties. Physiol. Plant. 159, 2-12. doi: $10.1111 /$ ppl.12475 
Jindal, S. (2020). "Microbes in soil and their metagenomics", in Microbial Diversity, Interventions and Scope, eds. S. Sharma, N. Sharma, M. Sharma (Singapore: Springer), 85-96. doi: 10.1007/978-981-15-4099-8_5

Juang, R. S., and Yeh, C. L. (2014). Adsorptive recovery and purification of prodigiosin from methanol/water solutions of Serratia marcescens fermentation broth. Biotechnol. Bioprocess Eng. 19, 159-168. doi: 10.1007/s12257-013-0547-2

Kalra, R., Conlan, X. A., and Goel, M. (2020). Fungi as a potential source of pigments: harnessing filamentous fungi. Front. Chem. 8:369. doi: $10.3389 /$ fchem.2020.00369

Kantifedaki, A., Kachrimanidou, V., Mallouchos, A., Papanikolaou, S., and Koutinas, A. A. (2018). Orange processing waste valorisation for the production of bio-based pigments using the fungal strains monascus purpureus and penicillium purpurogenum. J. Clean. Prod. 185, 882-890. doi: 10.1016/j.clepro.2018.03.032

Khaw, K. Y., Parat, M. O., Shaw, P. N., and Falconer, J. R. (2017). Solvent supercritical fluid technologies to extract bioactive compounds from natural sources: a review. Molecules 22:1186. doi: 10.3390/molecules22 071186

Kitada, K., Machmudah, S., Sasaki, M., Goto, M., Nakashima, Y., Kumamoto, S., et al. (2009). Supercritical $\mathrm{CO}_{2}$ extraction of pigment components with pharmaceutical importance from Chlorella vulgaris. J. Chem. Technol. Biotechnol. 84, 657-661. doi: 10.1002/jctb.2096

Kjærbølling, I., Mortensen, U. H., Vesth, T., and Andersen, M. R. (2019). Strategies to establish the link between biosynthetic gene clusters and secondary metabolites. Fungal Genet. Biol. J. 130, 107-121. doi: 10.1016/j.fgb.2019.06.001

Korumilli, T., Mishra, S., and Korukonda, J. R. (2020). Production of astaxanthin by Xanthophyllomyces dendrorhous on fruit waste extract and optimization of key parameters using taguchi method. J. Biochem. Tech. 11, 25-31.

Kot, A., Błazejak, S., Kieliszek, M., Gientka, I., Bryś, J., Reczek, L., et al. (2019). Effect of exogenous stress factors on the biosynthesis of carotenoids and lipids by Rhodotorula yeast strains in media containing agro-industrial waste. World J. Microbiol. Biotechnol. 35:157. doi: 10.1007/s11274-019-2732-8

Lagashetti, A., Dufossé, L., Singh, S. K., and Singh, P. (2019). Fungal pigments and their prospects in different industries. Microorganisms 7:604. doi: 10.3390/microorganisms 7120604

Lebeau, J., Venkatachalam, M., Fouillaud, M., Petit, T., Vinale, F., Dufossé, L., et al. (2017). Production and new extraction method of polyketide red pigments produced by ascomycetous fungi from terrestrial and marine habitats. J. Fungi. 3:34. doi: 10.3390/jof3030034

Liao, L., Su, S., Zhao, B., Fan, C., Zhang, J., Li, H., et al. (2019). Biosynthetic potential of a novel antarctic actinobacterium Marisediminicola antarctica ZS314T revealed by genomic data mining and pigment characterization. Mar. Drugs 17:388. doi: 10.3390/md170 70388

Lin, C. H., Lin, T. H., and Pan, T. M. (2017). Alleviation of metabolic syndrome by monascin and ankaflavin: the perspective of monascus functional foods. Food Funct. 8, 2102-2109. doi: 10.1039/c7fo00406k

Liu, J., Luo, Y., Guo, T., Tang, C., Chai, X., Zhao, W., et al. (2019). Cost-effective pigment production by Monascus purpureus using rice straw hydrolysate as substrate in submerged fermentation. J. Biosci. Bioeng. 129, 229-236. doi: 10.1016/j.jbiosc.2019.08.007

Lopes, F. C., Tichota, D. M., Pereira, J. Q., Seglin, J., Rios, A. O., and Brandelli, A. (2013). Pigment production by filamentous fungi on agroindustrial byproducts: an eco-friendly alternative. Appl. Biochem. Biotechnol. 171, 616-625. doi: 10.1007/s12010.013-0392-y

Luzzatto-Knaan, T., Melnik, A. V., and Dorrestein, P. C. (2015). Mass spectrometry tools and workflows for revealing microbial chemistry. Analyst 140, 4949-4966. doi: 10.1039/c5an00171d

Manchester, M., and Anand, A. (2017). Metabolomics: strategies to define the role of metabolism in virus infection and pathogenesis. Adv. Virus Res. 98, 57-81. doi: 10.1016/bs.aivir.2017.02.001

Mandakovic, D., Cintolesi, A., Maldonado, J., Mendoza, S. N., Aite, M., Gaete, A., et al. (2020). Genome-scale metabolic models of Microbacterium species isolated from a high altitude desert environment. Sci. Rep. 10:5560. doi: 10.1038/s41598-020-62130-8

Mapari, S. A. S., Meyer, A. S., Thrane, U., and Frisvad, J. C. (2009). Identification of potentially safe promising fungal cell factories for the production of polyketide natural food colorants using chemotaxonomic rationale. Microb. Cell Fact. 8:24. doi: 10.1186/1475-2859-8-24
Martínez, J. M., Delso, C., Álvarez, I., and Raso, J. (2020). Pulsed electric fieldassisted extraction of valuable compounds from microorganisms. Compr. Rev. Food Sci. Food Saf. 9, 530-552. doi: 10.1111/1541-4337.12512

Medina-Torres, N., Ayora-Talavera, T., Espinosa-Andrews, H., SánchezContreras, A., and Pacheco, N. (2017). Ultrasound assisted extraction for the recovery of phenolic compounds from vegetable sources. Agronomy 7:47. doi: 10.3390/agronomy7030047

Mohammad, S., Šamec, D., Tomczyk, M., Milella, L., Russo, D., Habtemariam, S., et al. (2020). Flavonoid biosynthetic pathways in plants: versatile targets for metabolic engineering. Biotechnol. Adv. 38:107316. doi: 10.1016/j.biotechadv.2018.11.005

Morales-Oyervides, L., Oliveira, J., Sousa-Gallagher, M. J., Zavala, A., and Montañez, J. (2017). Assessment of the dyeing properties of the pigments produced by Talaromyces spp. J. Fungi. 3:38. doi: 10.3390/jof3030038

Mussagy, C., Ebinuma, V., Gonzalez-Miquel, M., Coutinho, J., and Pereira, J. (2019). Protic ionic liquids as cell-disrupting agents for the recovery of intracellular carotenoids from yeast Rhodotorula glutinis CCT-2186. ACS Sustain. Chem. Eng. 7, 16765-16776 doi: 10.1021/acssuschemeng.9b04247

Nimnoi, P., and Lumyong, S. (2009). Improving solid-state fermentation of Monascus purpureus on agricultural products for pigment production. Food Bioprocess Technol. 4, 1384-1390. doi: 10.1007/s11947-009-0233-8

Noreña-Caro, D., and Benton, M. G. (2018). Cyanobacteria as photoautotrophic biofactories of high-value chemicals. J. $\mathrm{CO}_{2}$ Util. 28, 335-366. doi: 10.1016/j.jcou.2018.10.008

Novoveská, L., Ross, M. E., Stanley, M. S., Pradelles, R., Wasiolek, V., and Sassi, J. F. (2019). Microalgal carotenoids: a review of production, current markets, regulations, and future direction. Mar. Drugs 17:640. doi: 10.3390/md17110640

Okolie, C. L., Mason, B., and Critchley, A. T. (2019). "Seaweeds as a source of proteins for use in pharmaceuticals and high-value applications", in Novel Proteins for Food, Pharmaceuticals and Agriculture: Sources, Applications and Advances, ed. M. Hayes (Hoboken: Wiley-Blackwell), 217-238. doi: 10.1002/9781119385332.ch11

Palazzotto, E., and Weber, T. (2018). Omics and multi-omics approaches to study the biosynthesis of secondary metabolites in microorganisms. Curr. Opin. Microbiol. 45, 109-116. doi: 10.1016/j.mib.2018.03.004

Parmar, R., and Singh, C. (2018). A comprehensive study of eco-friendly natural pigment and its applications. Biochem. Biophys. Rep. 13, 22-26. doi: 10.1016/j.bbrep.2017.11.002

Parrot, D., Blümel, M., Utermann, C., Chianese, G., Krause, S., Kovalev, A., et al. (2019). Mapping the surface microbiome and metabolome of brown seaweed fucus vesiculosus by amplicon sequencing, integrated metabolomics and imaging techniques. Sci. Rep. 9:1061. doi: 10.1038/s41598-018-37914-8

Pasquet, V., Chérouvrier, J. R., Farhat, F., Thiéry, V., Piot, J. M., Bérard, J. B., et al. (2011). Study on the microalgal pigments extraction process: performance of microwave assisted extraction. Process Biochem. 46, 59-67. doi: 10.1016/j.procbio.2010.07.009

Quintieri, L., Zühlke, D., Fanelli, F., Caputo, L., Cosma, V., Logrieco, F. A., et al. (2019). Proteomic analysis of the food spoiler Pseudomonas fluorescens ITEM 17298 reveals the antibiofilm activity of the pepsin-digested bovine lactoferrin. Food Microbiol. 82, 177-193. doi: 10.1016/j.fm.2019. 02.003

Rajagopal, V., Ramakrishnan, P., Murugeshand, S., and Kunjithapatham, S. (2009). Microbial bioconversion of rice broken to food grade pigments. Global J. Biotechnol. Biochem. 4, 84-87.

Rambo, I. M., Dombrowski, N., Constant, L., Erdner, D., and Baker, B. J. (2020). Metabolic relationships of uncultured bacteria associated with the microalgae Gambierdiscus. Environ. Microbiol. 22, 1764-1783. doi: 10.1111/1462-2920.14878

Ramesh, C. H., Vinithkumar, N. V., Kirubagaran, R., Venil, C. K., and Dufossé, L. (2019). Multifaceted applications of microbial pigments: current knowledge, challenges and future directions for public health implications. Microorganisms 7:186. doi: 10.3390/microorganisms7070186

Rao, M. P. N., Xiao, M., and Li, W. J. (2017). Fungal and bacterial pigments: secondary metabolites with wide applications. Front. Microbiol. 8:1113. doi: $10.3389 /$ fmicb.2017.01113

Saini, D. K., Chakdar, H., Pabbi, S., and Shukla, P. (2020). Enhancing production of microalgal biopigments through metabolic and genetic engineering. Crit. Rev. Food Sci. Nutr. 60, 391-405. doi: 10.1080/10408398.2018.1533518 
Saini, D. K., Pabbi, S., and Shukla, P. (2018). Cyanobacterial pigments: perspectives and biotechnological approaches. Food Chem. Toxicol. 120, 616-624. doi: 10.1016/j.fct.2018.08.002

Sajjad, W., Din, G., Rafiq, M., Iqbal, A., Khan, S., Zada, S., et al. (2020). Pigment production by cold-adapted bacteria and fungi: colorful tale of cryosphere with wide range applications. Extremophiles 24, 447-473. doi: 10.1007/s00792-020-01180-2

Sen, T., Barrow, C. J., and Deshmukh, S. K. (2019). Microbial pigments in the food industry - challenges and the way forward. Front. Nutr. 6:7. doi: $10.3389 /$ fnut. 2019.0000

Sharma, R., and Ghoshal, G. (2019). Optimization of carotenoids production by Rhodotorula mucilaginosa (MTCC-1403) using agro-industrial waste in bioreactor: a statistical approach. Biotechnol. Rep. 25:e00407. doi: 10.1016/j.btre.2019.e00407

Shen, L., Liu, Y., Wang, N., Jiao, N., Xu, B., and Liu, X. (2018). Variation with depth of the abundance, diversity and pigmentation of culturable bacteria in a deep ice core from the Yuzhufeng Glacier, Tibetan Plateau. Extremophiles 22, 29-38. doi: 10.1007/s00792-017-0973-8

Silbir, S., and Goksungur, Y. (2019). Natural red pigment production by Monascus purpureus in submerged fermentation systems using a food industry waste: brewer's spent grain. Foods 8:161. doi: 10.3390/foods8050161

Silva, T. R., Tavares, R. S. N., Canela-Garayoa, R., Eras, J., Rodriguez, M., Neri, I., et al. (2019). Chemical characterization and biotechnological applicability of pigments isolated from antarctic bacteria. Mar. Biotechnol. 21, 416-429. doi: 10.1007/s10126-019-09892-z

Silveira, S. T., Daroit, D. J., and Brandelli, A. (2008). Pigment production by Monascus purpureus in grape waste using factorial design. LWT Food Sci. Technol. 41, 170-174. doi: 10.1016/j.lwt.2007.01.013

Silveira, S. T., Daroit, D. J., Sant'Anna, V., and Brandelli, A. (2013). Stability modeling of red pigments produced by Monascus purpureus in submerged cultivations with sugarcane bagasse. Food Bioprocess Technol. 6, 1007-1014. doi: 10.1007/s11947.011-0710-8

Singh, D. P., Khattar, J. S., Rajput, A., Chaudhary, R., and Singh, R. (2019). High production of carotenoids by the green microalga Asterarcys quadricellulare PUMCC 5.1.1 under optimized culture conditions. PLoS ONE 14:e221930. doi: 10.1371/journal.pone.0221930

Soares, A. T., Júnior, J. M., Lopes, R. G., Derner, R. B., and Filho, N. R. (2016). Improvement of the extraction process for high commercial value pigments from Desmodesmus sp. microalgae. J. Braz. Chem. Soc. 27, 1083-1093. doi: 10.5935/0103-5053.20160004

Sonani, R. R., Rastogi, R. P., Patel, R., and Madamwar, D. (2016). Recent advances in production, purification and applications of phycobiliproteins. World J. Biol. Chem. 7, 100-109. doi: 10.4331/wjbc.v7.i1.100

Song, L., Florea, B. I., Aston, P., Ichinose, K., Gubbens, J., Zhu, H., et al. (2014). Natural product proteomining, a quantitative proteomics platform, allows rapid discovery of biosynthetic gene clusters for different classes of natural products. Chem. Biol. 21, 707-718. doi: 10.1016/j.chembiol.2014. 03.011

Stincone, P., and Brandelli, A. (2020). Marine bacteria as source of antimicrobial compounds. Crit. Rev. Biotechnol. 40, 306-319, doi: 10.1080/07388551.2019.1710457

Tang, W., Wang, Y., Zhang, J., Cai, Y., and He, Z. (2019). Biosynthetic pathway of carotenoids in Rhodotorula and strategies for enhanced their production. J. Microbiol. Biotechnol. 29, 507-517. doi: 10.4014/jmb.180 1.01022

Tavanandi, H. A., and Raghavarao, K. S. M. S. (2019). Ultrasound-assisted enzymatic extraction of natural food colorant C-phycocyanin from dry biomass of Arthrospira platensis. LWT Food Sci. Technol. 118:108802. doi: 10.1016/j.lwt.2019.108802
Thiel, V., Costas, A. M. G., Fortney, N. W., Martínez, J. N., Tank, M., Roden, E. E., et al. (2019). "Candidatus Thermonerobacter thiotrophicus," a non-phototrophic member of the Bacteroidetes/Chlorobi with dissimilatory sulfur metabolism in hot spring. Front. Microbiol. 9:3159. doi: 10.3389/fmicb.2018.03159

Usmani, Z., Sharma, M., Sudheer, S., Gupta, V. K., and Bhat, R. (2020). Engineered microbes for pigment production using waste biomass. Curr. Genomics 21, 80-95. doi: 10.2174/1389202921999200330152007

Varasteh, T., Hamerski, L., Tschoeke, D., Lima, A. S., Garcia, G., Cosenza, C. A. N., et al. (2020). Conserved pigment profiles in phylogenetically diverse symbiotic bacteria associated with the corals Montastraea cavernosa and Mussismilia braziliensis. Microb. Ecol. doi: 10.1007/s00248-020-01551-4. [Epub ahead of print].

Venil, C. K., Devi, P. R., and Ahmand, W. A. (2020a). "Agro-industrial waste as substrates for the production of bacterial pigment," in Valorisation of Agro-industrial Residues - Volume I: Biological Approaches, eds. Z. Zakaria, R. Boopathy, J. Dib (Cham: Springer), 149-162. doi: 10.1007/978-3-030-39137-9_7

Venil, C. K., Dufossé, L., and Devi, P. R. (2020b). Bacterial pigments: sustainable compounds with market potential for pharma and food industry. Front. Sustain. Food Syst. 4:100. doi: 10.3389/fsufs.2020.00100

Venil, C. K., Zakira, Z. A., Usha, R., and Ahmad, W. A. (2014). Isolation and characterization of flexirubin type pigment from Chryseobacterium sp. UTM$3^{\mathrm{T}}$. Biocatal. Agric. Biotechnol. 3, 103-107. doi: 10.1016/j.bcab.2014.02.006

Wang, X., Tao, J., Wei, D., Shen, Y., and Tong, W. (2004). Development of an adsorption procedure for the direct separation and purification of prodigiosin from culture broth. Biotechnol. Appl. Biochem. 40, 277-280. doi: 10.1042/BA2003021

Xu, X., Tian, L., Zhang, S., Jiang, L., Zhang, Z., and Huang, H. (2019). Complete genome sequence of Janthinobacterium sp. B9-8, a violaceinproducing bacterium isolated from low-temperature sewage. Microb. Pathog. 128, 178-183. doi: 10.1016/j.micpath.2019.01.003

Yang, Y., Liu, B., Du, X., Li, P., Liang, B., Cheng, X., et al. (2015). Complete genome sequence and transcriptomics analyses reveal pigment biosynthesis and regulatory mechanisms in an industrial strain, Monascus purpureus YY-1. Sci. Rep. 5:8331. doi: 10.1038/srep08331

Yusuf, M., Shabbir, M., and Mohammad, F. (2017). Natural colorants: historical, processing and sustainable prospects. Nat. Prod. Bioprospect. 7, 123-145. doi: 10.1007/s13659-017-0119-9

Zerin, I., Farzana, N., Sayem, M., Anang, D. M., and Haider, J. (2020). "Potentials of natural dyes for textile applications", in Encyclopedia of Renewable and Sustainable Materials, eds. S. Hashmi, I. A. Choudhury (Oxford: Elsevier), 873-883. doi: 10.1016/B978-0-12-803581-8.11668-6

Zhou, B., Ma, Y., Tian, Y., Li, J., and Zhong, H. (2020). Quantitative proteomics analysis by sequential window acquisition of all theoretical mass spectra mass spectrometry reveals inhibition mechanism of pigments and citrinin production of Monascus response to high ammonium chloride concentration. J. Agric. Food Chem. 68, 808-817. doi: 10.1021/acs.jafc.9b05852

Conflict of Interest: The authors declare that the research was conducted in the absence of any commercial or financial relationships that could be construed as a potential conflict of interest.

Copyright (C) 2020 Pailliè-Jiménez, Stincone and Brandelli. This is an open-access article distributed under the terms of the Creative Commons Attribution License (CC $B Y)$. The use, distribution or reproduction in other forums is permitted, provided the original author(s) and the copyright owner(s) are credited and that the original publication in this journal is cited, in accordance with accepted academic practice. No use, distribution or reproduction is permitted which does not comply with these terms. 